\title{
Impaction of mandibular third molars after orthodontic treatment by the edgewise method: a retrospective study
}

\author{
Lucas Garcia SANTANA ${ }^{(a)}$ \\ Túlio Silva PEREIRA(a) \\ Izabella Barbosa FERNANDES(b) \\ Margareth Maria Gomes de \\ SOUZA(c) \\ Saul Martins PAIVA(b) \\ Maria Leticia RAMOS-JORGE(a) \\ Leandro Silva MARQUES(a) \\ (a) Universidade Federal dos Vales do \\ Jequitinhonha e Mucuri - UFVJM, School of \\ Dentistry, Department of Pediatric Dentistry \\ and Orthodontics, Diamantina, MG, Brazil. \\ (b) Universidade Federal de Minas Gerais - \\ UFMG, School of Dentistry, Department of \\ Pediatric Dentistry and Orthodontics, Belo \\ Horizonte, MG, Brazil. \\ (c) Universidade Federal do Rio de Janeiro, \\ School of Dentistry, Department of \\ Orthodontics, Rio de Janeiro, RJ, Brazil.
}

Declaration of Interests: The authors certify that they have no commercial or associative interest that represents a conflict of interest in connection with the manuscript.

Corresponding Author:

Lucas Garcia Santana

E-mail: lucasgarciasantana@gmail.com

https://doi.org/10.1590/1807-3107bor-2020.vol34.0065

Submitted: November 6, 2019

Accepted for publication: April 7, 2020

Last revision: May 19, 2020
Abstract: This study aimed to determine the incidence of mandibular third molar (M3) impaction after orthodontic treatment by edgewise appliances, and identify possible determinant factors of M3 impaction. A retrospective cohort study was conducted with 1154 patients. Complete orthodontic records were analyzed pretreatment and posttreatment, considering the following variables: type of Angle malocclusion, treatment with or without extraction of first premolars, overbite, stage of dentition, M3 prior angulation and duration of orthodontic treatment. Impaction was determined after radiographic evidence of total closure of the root apex. The chi-square test and Poisson regression $(p<0.05)$ were used for statistical analysis with a hierarchical approach. Rate ratios (RR) and 95\% confidence intervals (CI) were calculated. Mandibular M3 impaction incidence was $17 \%$. Overbite equal to or greater than $4 \mathrm{~mm}(\mathrm{RR}=1.23,95 \% \mathrm{CI}$ : 1.11-1.26, $p<0.001)$, prior mesial angulation of M3 (RR $=0.59,95 \% \mathrm{CI}: 0.52-0.68$, $\mathrm{p}<0.001$ ), non-extraction of first premolars ( $R R=1.06,95 \% \mathrm{CI}$ : 1.01-1.12, $\mathrm{P}=0.019)$ and orthodontic treatment time equal to or less than three years $(\mathrm{RR}=0.94$. 95\%CI: 0.90-0.99, $\mathrm{p}<0.014)$ were significantly associated with impacted M3. There was no correlation between the type of Angle malocclusion and the risk of impaction. In conclusion, the incidence of mandibular M3 impaction was considered low. The main pretreatment factors directly involved in impaction were mesioangulation of M3 and overbite equal to or greater than $4 \mathrm{~mm}$. Orthodontic treatment with extraction of first premolars and treatment time greater than 3 years reduce the risk of impaction.

Keywords: Tooth, Impacted; Orthodontics; Third Molar.

\section{Introduction}

Impacted third molars (M3) are common in modern society, more likely in the mandible, with a prevalence rate of $24 \%$ that can extend up to roughly $68 \%$ throughout the world. ${ }^{1,2}$ This condition can generate several complications, such as caries, external root resorption of adjacent teeth, localized periodontal problems, infections, and mandible fractures. ${ }^{3,4,5}$ The etiology of M3 impaction has been associated with several factors, including a large variation in tooth morphology, prior tooth position and eruption pathway, root development, and deficient retromolar space. ${ }^{1,6}$ 
It has also been speculated that some occlusal and skeletal features may influence M3 impaction. A Class II dental and skeletal relationship with a shorter, narrower, and more acute gonial angle was found in association with an impacted M3. ${ }^{6}$ In addition, vertical condylar growth may also lead to limited anterior remodeling of the mandibular ramus, leading to not enough space for a lower M3 to erupt. ${ }^{7,8,9}$

Several authors have defended the principle of premolar extraction to improve the position and angle of an impacted M3, thereby favoring its complete euption. ${ }^{10,1012,13}$ A critical appraisal of the literature finds that the main limitations of these studies are related to the unrepresentativeness of the sample, non-standardized use of the type of appliance and orthodontic mechanics, methodological differences regarding evaluations and different follow-up times. ${ }^{10,12,13,14,15}$

In this sense, orthodontists would improve treatment strategies if they could accurately predict the variables associated with M3 eruption. ${ }^{14}$ However, recent systematic reviews reveal that orthodontists are unable to predict $\mathrm{M} 3$ eruption by examining a panoramic radiograph. ${ }^{16,17}$ Furthermore, previous studies have used only the predictive value of available space and tooth position, while neglecting the possible influence of other variables. ${ }^{1,14,15,16}$ Thus, a possible consequence is that prophylactic extraction of M3 may be occurring in a disorderly fashion and with no defined criteria.

For these reasons, the aims of the present study were to assess the incidence of M3 impaction in patients treated with the edgewise orthodontic method, and identify possible determinant factors.

\section{Methodology}

We followed theSTROBE statement ${ }^{18}$ for transparent reporting of this retrospective cohort study.

\section{Study population}

This retrospective cohort study consisted of a convenience sample of patients who underwent orthodontic treatment using a pure edgewise method, as part of the Postgraduate Orthodontic Program of Universidade Federal do Rio de Janeiro, Brazil.
Sample size was calculated using OpenEpi ${ }^{\circledR}$ software, (https://www.openepi.com/SampleSize/SSCC.htm), and was performed with the following parameters: $95 \%$ confidence interval $(\mathrm{CI})$, power of $80 \%$, percentage of $75 \%$ positive individuals among the unexposed group, and rate ratio (RR) of 1.5 (pilot study with $10 \%$ of the sample). The minimum required sample was set at 968 records. Another 186 records were added to the sample to compensate for possible losses. A total of 1,154 pretreatment and posttreatment (immediately after removal of the orthodontic appliance) records were analyzed. The selection criteria excluded records of unconcluded orthodontic treatment, patients with severe craniofacial deformities, clefts and radiographic signs of pathologies, such as cysts, tumors, congenitally missing M3 teeth, and radiographs of poor quality. No patient was undergoing retreatment. Treatment was provided by resident dentists supervised by experienced clinicians working in the orthodontic clinic of the same university.

The final sample comprised 1,037 orthodontic records of patients with a mean age of 15.3 (SD, 0.92) years. Mean duration of the active phase of treatment was 3.24 years. Follow-up panoramic radiographs were analyzed to assess the M3 condition, and M3 was considered impacted only when no buccal or lingual cusps were present at the level of the occlusal plane, and the radiographic confirmed total closure of the root apex. ${ }^{11}$ The radiographic distortion was not so significant that it caused diagnostic errors in dental impaction.

\section{Data collection}

The independent variables were acquired from all the records by analyzing the clinical charts, and included demographic characteristics (age at onset of treatment and gender), pretreatment diagnosis and other relevant information, such as treatment with or without extraction of the four first premolars, malocclusion according to the Angle classification (Class I, Class II and Class III), overbite, stage of dentition (mixed or permanent) and duration of the orthodontic treatment. The angle of the M3 prior to orthodontic treatment was based on the Winter classification, ${ }^{19}$ which refers to the angle formed between the longitudinal axes of the second molar and 
the M3. Thus, the vertical $\left(10^{\circ}\right.$ to $\left.-10^{\circ}\right)$, mesioangular $\left(11^{\circ}\right.$ a $\left.79^{\circ}\right)$, horizontal $\left(80^{\circ}\right.$ to $\left.100^{\circ}\right)$, and distoangular $\left(-11^{\circ}\right.$ a $\left.-79^{\circ}\right)$ previous $\mathrm{M} 3$ positions were determined, among other types $\left(\geq 111^{\circ}\right.$ or $\left.\leq-80^{\circ}\right)$.

\section{Training and calibration exercises}

The training and calibration exercises of the examiners were performed by two orthodontists with at least eight years of clinical experience, with a random selection of $10 \%$ of all the radiographs. Their evaluation was performed considering impaction and tooth position. M3 impaction was evaluated using panoramic radiographs pre- and post-orthodontic treatment, using a negatoscope with standard light intensity. The minimum kappa coefficients for intraexaminer and interexaminer agreement on a tooth-by-tooth basis were 0.93 and 0.88 , respectively.

\section{Statistical analysis}

The results were entered into a database and analyzed using the Statistical Package for Social Sciences (version 20.0, SPSS, Chicago, USA). Absolute and relative frequencies were studied first. A hierarchical approach was employed to select the variables, ${ }^{20}$ which were grouped within a hierarchy of categories from distal to proximal determinants. The chi-square test was used to exclude variables with a $P$-value $<0.20$. For each level, Poisson regression analysis with robust variance was used to correlate M3 impaction (dependent variable) with the characteristics of each patient, treatment and dentition (in that order). Explanatory variables were selected for the final model when $\mathrm{p}$-value was $<0.05$ after adjustment of the variables on the same or previous level of the determinants. Proportion ratios (PRs) and 95\% CI were calculated.

\section{Results}

The incidence of M3 impaction after orthodontic treatment was $17 \%(n=176)$. The female gender accounted for $56 \%$ of the patients, and was not associated with M3 impaction ( $\mathrm{p}>0.05)$.

The frequency between impacted M3 and independent variables is shown in Table1. M3 impaction was significantly associated with the extraction of the first premolars ( $p<0.001)$, duration of treatment equal to or less than three years ( $p=0.001)$, overbite equal to or greater than $4 \mathrm{~mm}(\mathrm{p}<0.001)$, Class I $(p=0.032)$ and Class II Division $1(p=0.004)$, prior mesioangular M3 ( $<<0.001)$, prior distoangular M3 $(p<0.001)$, prior vertical M3 $(p<0.001)$ and prior horizontal M3 ( $<<0.001)$.

The univariate analysis revealed that the dependent variable (M3 impaction) was associated with the non-extraction of the four first premolars ( $P R=1.16$, 95\%CI: 1.09-1.23), treatment time greater than three years (PR $=0.89,95 \% C I$ : $0.85-0.95)$, overbite equal to or greater than $4 \mathrm{~mm}(\mathrm{PR}=1.37,95 \% \mathrm{CI}$ : 1.21-1.56), Class I (PR $=0.94,95 \% C I: 0.89-0.99)$ and Class II Division 1 (PR = 1.09, 95\%CI: 1.03-1.15), and prior mesioangular M3 ( $\mathrm{PR}=0.89,95 \% \mathrm{CI}$ : 0.81-0.99) (Table 2).

Table 3 displays the covariates that remained significantly associated with M3 impaction $(p<0.05)$ after applying the final hierarchical Poisson regression model. The following pretreatment dentition characteristics were associated with M3 impaction: overbite equal to or greater than $4 \mathrm{~mm}$ increases the risk by $23 \%(\mathrm{RR}=1.23,95 \% \mathrm{CI}$ : $1.11-1.26)$, and absence of mesioangular M3 reduces the risk by $41 \%$ ( RR $=0.59,95 \% C I$ : $0.52-0.68)$. Orthodontic treatment without extraction of the first premolars increases the risk of $\mathrm{M} 3$ impaction by $6 \%(\mathrm{RR}=1.06$, $95 \%$ CI: 1.01-1.12), whereas a treatment time greater than three years reduces the risk of impaction by $6 \%(\mathrm{RR}=0.94 .95 \% \mathrm{CI}: 0.90-0.99)$.

\section{Discussion}

This study showed that the pretreatment variables associated with impaction of M3 were prior mesioangular positioning of M3 $\left(11^{\circ}\right.$ to $\left.79^{\circ}\right)$ in relation to the second molar, and an overbite equal to or greater than $4 \mathrm{~mm}$. Treatment variables associated with reduced risk of impaction were extraction of first premolars, and treatment time greater than three years. No association was found between the type of Angle malocclusion and the risk of impaction. Our results might support a previous finding that extraction treatment of the first premolar can reduce the risk of mandibular M3 impaction, and that mesioangular impaction is the most often 
Impaction of mandibular third molars after orthodontic treatment by the edgewise method: a retrospective study

Table 1. Analysis of relationship between impaction of third molar and independent variables.

\begin{tabular}{|c|c|c|c|c|c|}
\hline \multirow{3}{*}{ Variables } & \multicolumn{2}{|c|}{ Impaction of third molar } & \multirow{3}{*}{ Total } & \multirow{3}{*}{$p$-value } & \multirow{3}{*}{ Cohen } \\
\hline & Yes & No & & & \\
\hline & n (\%) & n (\%) & & & \\
\hline \multicolumn{6}{|l|}{ Gender } \\
\hline Female & $90(15.9)$ & $485(84.3)$ & $575(100)$ & $0.207^{*}$ & 0.039 \\
\hline Male & $86(18.6)$ & $376(81.4)$ & $462(100)$ & & \\
\hline \multicolumn{6}{|c|}{ Extraction of 4 premolar } \\
\hline No & $97(24.4)$ & $300(75.6)$ & $397(100)$ & $<0.001^{*}$ & 0.157 \\
\hline Yes & 79 (12.3) & $561(87.7)$ & $640(100)$ & & \\
\hline \multicolumn{6}{|l|}{ Treatment time } \\
\hline$\leq 3$ years & $19(9.2)$ & $188(90.8)$ & $207(100)$ & $0.001^{c}$ & 0.104 \\
\hline$>3$ years & $157(18.9)$ & $673(81.1)$ & $830(100)$ & & \\
\hline \multicolumn{6}{|l|}{ Dentition (T1) } \\
\hline Mixed & $106(17.5)$ & $499(82.5)$ & $605(100)$ & $0.578^{*}$ & 0.017 \\
\hline Permanent & $70(16.2)$ & $362(83.8)$ & $432(100)$ & & \\
\hline \multicolumn{6}{|l|}{ Overbite (T1) } \\
\hline$\geq 4 \mathrm{~mm}$ & $53(37.1)$ & $90(62.9)$ & $143(100)$ & $<0.001^{*}$ & 0.214 \\
\hline$<4 \mathrm{~mm}$ & $123(13.8)$ & $771(86.2)$ & $894(100)$ & & \\
\hline \multicolumn{6}{|l|}{ Class I (T1) } \\
\hline Yes & $51(13.6)$ & $323(86.4)$ & $374(100)$ & $0.032^{c}$ & 0.067 \\
\hline No & 125 (18.9) & $538(81.1)$ & $663(100)$ & & \\
\hline \multicolumn{6}{|c|}{ Class II, Division 1 (T1) } \\
\hline Yes & $103(20.4)$ & $401(83.5)$ & $504(100)$ & $0.004^{c}$ & 0.090 \\
\hline No & $73(13.7)$ & $460(87.4)$ & $533(100)$ & & \\
\hline \multicolumn{6}{|c|}{ Class II, Division 2 (T1) } \\
\hline Yes & $15(13.1)$ & $106(87.6)$ & $121(100)$ & $0.154^{*}$ & 0.044 \\
\hline No & $161(14.7)$ & $755(82.4)$ & $916(100)$ & & \\
\hline \multicolumn{6}{|l|}{ Class III (T1) } \\
\hline Yes & 7 (18.9) & $30(81.1)$ & $37(100)$ & $0.748^{*}$ & 0.010 \\
\hline No & $169(16.9)$ & $831(83.1)$ & $1000(100)$ & & \\
\hline \multicolumn{6}{|c|}{ M3 mesioangular ( $\mathrm{T} 1$ ) } \\
\hline Yes & $142(99.3)$ & $1(0.7)$ & $143(100)$ & $<0.001^{*}$ & 0.899 \\
\hline No & $28(3.2)$ & $866(96.8)$ & $894(100)$ & & \\
\hline \multicolumn{6}{|c|}{ M3 distoangular (T1) } \\
\hline Yes & $6(100)$ & $0(0)$ & $6(100)$ & $<0.001^{* *}$ & 0.196 \\
\hline No & $168(16.2)$ & $862(83.8)$ & $1030(100)$ & & \\
\hline \multicolumn{6}{|c|}{ M3 molar horizontal (T1) } \\
\hline Yes & $24(100)$ & $0(0)$ & $24(100)$ & $<0.001^{* *}$ & 0.363 \\
\hline No & $149(14.7)$ & $863(85.3)$ & $1012(100)$ & & \\
\hline \multicolumn{6}{|c|}{ M3 molar vertical ( $\mathrm{T} 1)$} \\
\hline Yes & $4(100)$ & $0(0)$ & $4(100)$ & $0.001^{* *}$ & 0.138 \\
\hline No & $172(16.6)$ & $860(83.4)$ & $1032(100)$ & & \\
\hline
\end{tabular}

*Pearson Qui-Square test; "*Fisher's exact test. M3: third molar. 
Table 2. Univariate analysis for association between impaction of third molar, characteristics of dentition and characteristics of treatment.

\begin{tabular}{|c|c|c|}
\hline Covariates & Robust RR* $(95 \% \mathrm{Cl})$ & $p$-value** \\
\hline \multicolumn{3}{|l|}{ Gender } \\
\hline Female & 1 & \\
\hline Male & $0.96(0.91-1.02)$ & 0.210 \\
\hline \multicolumn{3}{|c|}{ Extraction of 4 premolar } \\
\hline Yes & 1 & \\
\hline No & $1.16(1.09-1.24)$ & $<0.001$ \\
\hline \multicolumn{3}{|c|}{ Treatment time } \\
\hline$\leq 3$ years & 1 & \\
\hline$>3$ years & $0.89(0.85-0.95)$ & $<0.001$ \\
\hline \multicolumn{3}{|l|}{ Overbite } \\
\hline$<4 \mathrm{~mm}$ & 1 & \\
\hline$\geq 4 \mathrm{~mm}$ & $1.37(1.21-1.56)$ & $<0.001$ \\
\hline \multicolumn{3}{|l|}{ Class I } \\
\hline Yes & 1 & \\
\hline No & $0.94(0.89-0.99)$ & 0.038 \\
\hline \multicolumn{3}{|c|}{ Class II, Division 1} \\
\hline Yes & 1 & \\
\hline No & 1.09 (1.03-1.15) & 0.003 \\
\hline \multicolumn{3}{|c|}{ Class II, Division 2} \\
\hline Yes & 1 & \\
\hline No & $0.93(0.87-1.00)$ & 0.062 \\
\hline \multicolumn{3}{|c|}{ M3 mesioangular (T1) } \\
\hline Yes & 1 & \\
\hline No & $0.89(0.81-0.99)$ & 0.030 \\
\hline
\end{tabular}

"RR: Rate Ratio; ${ }^{* *}$ Calculated by Wald chi-square.

seen orientation. ${ }^{1,21}$ However, one major weakness of any similar study is not having a large enough and standardized sample, a lack which may create sampling bias.

We provided an orthodontic pretreatment prediction factor for M3 impaction (the mesioangulation of M3), thus questioning previous recommendations that only posttreatment angulation may be a clinically useful predictor. ${ }^{6,21,22}$ Some evidence suggests that successful eruption of lower $\mathrm{M} 3$ requires that the angle between the second molar and $\mathrm{M} 3$ be greater than $40^{\circ}$ at 10 years old. Afterwards, this angle would adjust physiologically to eventually become a right angle, by the time the lower M3 is completely erupted..$^{6,23}$
Table 3. Final poisson regression model for covariates associated with impacted third molar.

\begin{tabular}{|c|c|c|}
\hline Covariates & Robust RR** $(95 \% \mathrm{Cl})$ & $\mathrm{p}$-value $* * *$ \\
\hline \multicolumn{3}{|c|}{ Characteristics of patient } \\
\hline \multicolumn{3}{|l|}{ Gender } \\
\hline Female & 1 & \\
\hline Male & $0.96(0.91-1.02)$ & 0.178 \\
\hline \multicolumn{3}{|c|}{ Characteristics of treatment - level $1^{a}$} \\
\hline \multicolumn{3}{|c|}{ Extraction of 4 premolars } \\
\hline Yes & 1 & \\
\hline No & $1.16(1.09-1.23)$ & $<0.001$ \\
\hline \multicolumn{3}{|l|}{ Treatment time } \\
\hline$\leq 3$ years & 1 & \\
\hline$>3$ years & $0.89(0.85-0.94)$ & $<0.001$ \\
\hline \multicolumn{3}{|c|}{ Characteristics of dentition - level $2^{*}$} \\
\hline \multicolumn{3}{|l|}{ Overbite } \\
\hline$<4 \mathrm{~mm}$ & 1 & \\
\hline$\geq 4 \mathrm{~mm}$ & $1.23(1.11-1.26)$ & $<0.001$ \\
\hline \multicolumn{3}{|c|}{ M3 mesioangular ( $\mathrm{T} 1)$} \\
\hline Present & 1 & \\
\hline Absent & $0.59(0.52-0.68)$ & $<0.001$ \\
\hline \multicolumn{3}{|c|}{ Extraction of 4 premolar } \\
\hline Yes & 1 & \\
\hline No & $1.06(1.01-1.12)$ & 0.019 \\
\hline \multicolumn{3}{|l|}{ Treatment time } \\
\hline$\leq 3$ years & 1 & \\
\hline$>3$ years & $0.94(0.90-0.99)$ & 0.014 \\
\hline
\end{tabular}

"Model adjusted for the variables significant in the final model of previous levels; " RR: Rate Ratio; ${ }^{* * *}$ Calculated by Wald Chi-square test.

Our results contradict this, since patients who had an angle of $11^{\circ}$ to $79^{\circ}$ presented a higher risk of impaction after the root apex closure, which represents the end of the eruption pathway. The initial mesioangulation leaves the pathway of M3 eruption angled toward the surface of the adjacent tooth, which can block its movement and lead to impaction. Prior angulation of M3 is a specially important observation that should be included in the planning of an orthodontic treatment as supplementary information for making a clinical decision, especially regarding borderline cases contemplating tooth extraction or nonextraction.

Another risk factor found in this study for mandibular M3 impaction was pretreatment overbite 
equal to or greater than $4 \mathrm{~mm}$. We believe that the mandibular growth pattern may help understand this association. A small gonial angle is related to an anterior rotation of the mandible during the growth period, ${ }^{6,7}$ leading to an increase in overbite. The association among such factors as small gonial angle, anterior mandibular growth pattern, and risk of M3 impaction is known, since this pattern of mandibular rotation leads to a limited remodeling of the mandibular ramus. ${ }^{21,23}$ Thus, increased overbite may be a clinical characteristic associated with lower risk of $\mathrm{M} 3$ impaction.

We found no association between Angle classification malocclusion and M3 impaction in the final regression model. This was surprising, because several studies reported an association between a Class II skeletal and dental relationship and M3 impaction. The total length of the mandible in patients with impacted M3, may be smaller than in patients without impacted molars, thus diminishing the retromolar space. ${ }^{6,24}$ Other associated Class II skeletal characteristics are an acute gonial angle and a narrow mandible. ${ }^{6}$ Likewise, it is expected that the space-to-width ratio in Class III patients will attain the values needed for eruption of the lower $M 3$, thus acting as a protective factor against impaction, ${ }^{9}$ even though this was not confirmed by our results. This disagreement may be attributed to how we evaluated the sagittal relationship, in which we observed the dental relationship, versus how other studies evaluate dental and skeletal relationships.

An important finding herein was the influence of orthodontic treatment performed with extraction of the first premolars, considering that the risk of M3 impaction in patients undergoing first premolar removal was reduced (6\%). Recent studies have reported a similar yet stronger association. ${ }^{10,11,12,13,14,25}$ The hypothesis is that orthodontic treatment with premolars extraction favors mesial movement and uprighting of molars, with a concomitant increase in retromolar space, thereby allowing successful eruption of M3. ${ }^{12,14,25}$ Opting not to extract premolars is tantamount to requiring more frequent surgical removal of M3. Thus, orthodontic treatment without extraction of premolars is not always a treatment without extraction. ${ }^{26}$ Nevertheless, planning for cases of premolar extraction when there is a risk of M3 impaction should be done carefully. The amount of posterior space created for $\mathrm{M} 3$ eruption will depend on the amount of distal movement of the canine. Canine retraction with maximum anchorage will not create the space needed in the posterior portion in the arch, thus risking extraction of four mandibular teeth.

When the treatment time was greater than three years, the risk of M3 impaction was lower than it would have been with a shorter treatment time. The factors that influence longer orthodontic treatment time can be broken down into four components: sociodemographic characteristics, malocclusion characteristics, patient cooperation and treatment method. ${ }^{27}$ Regarding the treatment method, previous studies have demonstrated that the extraction of the first premolars was significantly associated with a longer treatment time. This association of premolar extraction and treatment time is strongly associated with a lower frequency of M3 extraction after orthodontic treatment. ${ }^{28}$ However, in our study even after applying the hierarchical statistical approach, the duration of treatment continued to reduce the risk of M3 impaction.

The decision about what factors to include in the statistical model should be based on a conceptual framework that describes the hierarchical relationships between the risk factors. We have used conceptual hierarchical frameworks to study the determinants of M3 impaction. These frameworks have provided guidance for using multivariate techniques and interpreting their results according to the knowledge of demographic and biological factors. Multivariate analysis, often used to predict risk, is based entirely on statistical associations, rather than any conceptual basis for determining the interrelationships between factors, and all explanatory variables are treated as belonging to the same hierarchical level. When assessing whether a variable has a direct effect on or is affected by other factors, a hierarchical analytical approach is preferable. ${ }^{20}$ This may be considered an advantage of this study.

A possible weakness of this study is the age and phase of dentition of the sample (some patients started treatment in the mixed dentition). The root apex of M3 closes at a mean age of approximately 20 years. ${ }^{29}$ 
The mean posttreatment age of our sample was slightly younger than this, and may have contributed to the low incidence of impaction found. However, the identification of the determining factors was not influenced, since the statistical hierarchical approach includes only the cases where the impaction was confirmed by the root apex closure. This provided a more homogeneous sample at the time of the dependent variable analysis (M3 impaction). Other potentially related factors not covered by the analysis may be related to M3 impaction. These include amount of pretreatment crowding, ${ }^{30}$ pattern of mandibular and condylar growth, available retromolar space and residual mandibular growth in Class III patients. ${ }^{9}$

The clinical implications of our findings might guide clinical actions and improve the understanding M3 impaction behavior. In sum, mesioangulation of M3 and a pronounced overbite before orthodontic treatment are predictive dental and occlusal characteristics of future disturbances regarding M3 eruption, and indicate orthodontic treatment with premolar extraction in borderline cases. Thus, the possibility of monitoring and improving M3 eruption conditions during orthodontic treatment could prevent late-onset complications regarding tooth positioning.

\section{Conclusion}

A low incidence of mandibular M3 impaction was found in orthodontic patients treated with the edgewise method. Pretreatment factors directly involved in impaction were mesioangulation of $\mathrm{M} 3$, and overbite equal to or greater than $4 \mathrm{~mm}$. Orthodontic treatment with extraction of first premolars and treatment time greater than 3 years reduce the risk of impaction.

\section{Acknowledgements}

This study was supported by CAPES (Fundação Coordenação de Aperfeiçoamento de Pessoal de Nível Superior - Code: 88881.336658/ 2019-01), Conselho Nacional de Desenvolvimento Científico e Tecnológico (CNPq) and Fundação de Amparo à Pesquisa do Estado de Minas Gerais (FAPEMIG).

\section{References}

1. Carter K, Worthington S. Predictors of third molar impaction: a systematic review and meta-analysis. J Dent Res. 2016 Mar;95(3):267-76. https://doi.org/10.1177/0022034515615857

2. Quek SL, Tay CK, Tay KH, Toh SL, Lim KC. Pattern of third molar impaction in a Singapore Chinese population: a retrospective radiographic survey. Int J Oral Maxillofac Surg. 2003 Oct;32(5):548-52. https://doi.org/10.1016/S0901-5027(03)90413-9

3. Chen Y, Zheng J, Li D, Huang Z, Huang Z, Wang X, et al. Three-dimensional position of mandibular third molars and its association with distal caries in mandibular second molars: a cone beam computed tomographic study. Clin Oral Investig. 2020 Jan. https://doi. org/10.1007/s00784-020-03203-w

4. Armond AC, Martins CC, Glória JC, Galvão EL, Santos CR, Falci SG. Influence of third molars in mandibular fractures. Part 1: mandibular angle-a meta-analysis. Int J Oral Maxillofac Surg. 2017 Jun;46(6):716-29. https://doi.org/10.1016/j.ijom.2017.02.1264

5. Li D, Tao Y, Cui M, Zhang W, Zhang X, Hu X. External root resorption in maxillary and mandibular second molars associated with impacted third molars: a cone-beam computed tomographic study. Clin Oral Investig. 2019 Dec;23(12):4195-203. https://doi. org/10.1007/s00784-019-02859-3

6. Richardson ME. The etiology and prediction of mandibular third molar impaction. Angle Orthod. 1977 Jul;47(3):165-72. https://doi.org/ 10.1043/0003-3219(1977)047<0165:teapom>2.0.co;2

7. Biörk A. Prediction of mandibular growth rotation. Am J Orthod. 1969 Jun;55(6):585-99. https://doi. org/10.1016/0002-9416(69)90036-0

8. Saysel MY, Meral GD, Kocadereli I, Taşar F. The effects of first premolar extractions on third molar angulations. Angle Orthod. 2005 Sep;75(5):719-22. https://doi.org/10.1043/0003-3219(2005)75[719:TEOFPE]2.0.CO;2

9. Jakovljevic A, Lazic E, Soldatovic I, Nedeljkovic N, Andric M. Radiographic assessment of lower third molar eruption in different anteroposterior skeletal patterns and age-related groups. Angle Orthod. 2015 Jul;85(4):577-84. https://doi.org/10.2319/062714-463.1

10. Kim TW, Artun J, Behbehani F, Artese F. Prevalence of third molar impaction in orthodontic patients treated nonextraction and with extraction of 4 premolars. Am J Orthod Dentofacial Orthop. 2003 Feb;123(2):138-45. https://doi.org/10.1067/mod.2003.13 
- Impaction of mandibular third molars after orthodontic treatment by the edgewise method: a retrospective study

11. Artun J, Thalib L, Little RM. Third molar angulation during and after treatment of adolescent orthodontic patients. Eur J Orthod. 2005 Dec;27(6):590-6. https://doi.org/10.1093/ejo/cji049

12. Jain S, Valiathan A. Influence of first premolar extraction on mandibular third molar angulation. Angle Orthod. 2009 Nov;79(6):1143-8. https://doi.org/10.2319/100708-525R.1

13. Celikoglu M, Kamak H, Akkast I, Oktay H. Effects of orthodontic treatment and premolar extractions on the mandibular third molars. Aust Orthod J. 2010 Nov;26(2):160-4.

14. Livas C, Delli K. Does Orthodontic extraction treatment improve the angular position of third molars? A systematic review. J Oral Maxillofac Surg. 2017 Mar;75(3):475-83. https://doi.org/10.1016/i.joms.2016.10.035

15. Abu Alhaija ES, AlBhairan HM, AlKhateeb SN. Mandibular third molar space in different antero-posterior skeletal patterns. Eur J Orthod. 2011 Oct;33(5):570-6. https://doi.org/10.1093/ejo/cjq125

16. Costa MG, Pazzini CA, Pantuzo MC, Jorge ML, Marques LS. Is there justification for prophylactic extraction of third molars? A systematic review. Braz Oral Res. 2013 Mar-Apr;27(2):183-8. https://doi.org/10.1590/S1806-83242013000100024

17. Bastos AC, Oliveira JB, Mello KF, Leão PB, Artese F, Normando D. The ability of orthodontists and oral/maxillofacial surgeons to predict eruption of lower third molar. Prog Orthod. 2016 Dec;17(1):21. https://doi.org/10.1186/s40510-016-0134-0

18. Elm E, Altman DG, Egger M, Pocock SJ, Gøtzsche PC, Vandenbroucke JP. The Strengthening the Reporting of Observational Studies in Epidemiology (STROBE) statement: guidelines for reporting observational studies. J Clin Epidemiol. 2008 Apr;61(4):344-9. https://doi. org/10.1016/i.jclinepi.2007.11.008

19. Hashemipour MA, Tahmasbi-Arashlow M, Fahimi-Hanzaei F. Incidence of impacted mandibular and maxillary third molars: a radiographic study in a Southeast Iran population. Med Oral Patol Oral Cir Bucal. 2013 Jan;18(1):e140-5. https://doi.org/10.4317/ medoral.18028

20. Victora CG, Huttly SR, Fuchs SC, Olinto MT. The role of conceptual frameworks in epidemiological analysis: a hierarchical approach. Int J Epidemiol. 1997 Feb;26(1):224-7. https://doi.org/10.1093/ije/26.1.224

21. Behbehani F, Artun J, Thalib L. Prediction of mandibular third-molar impaction in adolescent orthodontic patients. Am J Orthod Dentofacial Orthop. 2006 Jul;130(1):47-55. https://doi.org/10.1016/i.ajodo.2006.03.002

22. Erdem D, Ozdiler E, Memikoğlu UT, Başpinar E. Third molar impaction in extraction cases treated with the Begg technique. Eur J Orthod. 1998 Jun;20(3):263-70. https://doi.org/10.1093/ejo/20.3.263

23. Altonen M, Haavikko K, Mattila K. Developmental position of lower third molar in relation to gonial angle and lower second molar. Angle Orthod. 1977 Oct;47(4):249-55. https://doi.org/10.1043/0003-3219(1977)047<0249:DPOLTM>2.0.CO;2

24. Capelli J Jr. Mandibular growth and third molar impaction in extraction cases. Angle Orthod. 1991;61(3):223-9.

25. Tarazona B, Paredes V, Llamas JM, Cibrian R, Gandía JL. Influence of first and second premolar extraction or non-extraction treatments on mandibular third molar angulation and position. A comparative study. Med Oral Patol Oral Cir Bucal. 2010 Sep;15(5):e760-6. https://doi.org/10.4317/medoral.15.e760

26. Kandasamy S, Woods MG. Is orthodontic treatment without premolar extractions always non-extraction treatment? Aust Dent J. 2005 Sep;50(3):146-51. https://doi.org/10.1111/j.1834-7819.2005.tb00353.x

27. Skidmore KJ, Brook KJ, Thomson WM, Harding WJ. Factors influencing treatment time in orthodontic patients. Am J Orthod Dentofacial Orthop. 2006 Feb;129(2):230-8. https://doi.org/10.1016/i.ajodo.2005.10.003

28. Turbill EA, Richmond S, Wright JL. The time-factor in orthodontics: what influences the duration of treatments in National Health Service practices? Community Dent Oral Epidemiol. 2001 Feb;29(1):62-72. https://doi.org/10.1034/j.1600-0528.2001.00010.x

29. Sisman Y, Uysal T, Yagmur F, Ramoglu SI. Third-molar development in relation to chronologic age in Turkish children and young adults. Angle Orthod. 2007 Nov;77(6):1040-5. https://doi.org/10.2319/101906-430.1

30. Dierkes DD. An investigation of the mandibular third molars in orthodontic cases. Angle Orthod. 1975 Jul;45(3):207-12. https://doi.org/ 10.1043/0003-3219(1975)045<0207:AIOTMT>2.0.CO;2 